\title{
An experimental investigation of turbulent flow heat transfer through tube with rod-pin insert
}

\author{
M. A. K. Chowdhuri ${ }^{1 *}$, R. A. Hossain ${ }^{2}$, M.A.R. Sarkar ${ }^{3}$ \\ ${ }^{1,3}$ Department of Mechanical Engineering, Bangladesh University of Engineering \& Technology, Dhaka-1000, BANGLADESH \\ ${ }^{2}$ Department of Mechanical Engineering, University of Alberta, Canada \\ ${ }^{*}$ Corresponding Author: \\ Current address: Department of Mechanical Engineering, University of Alberta, Canada, \\ e-mail: khanchow@ualberta.ca, Tel+1-780 7527568
}

\begin{abstract}
An experimental investigation has been carried out to study the turbulent flow heat transfer and to determine the pressure drop characteristics of air, flowing through a tube with insert. An insert of special geometry is used inside the tube. The test section is electrically heated, and air is allowed to flow as the working fluid through the tube by means of a blower. Air velocity, air inlet and outlet temperature, local wall temperature and the pressure drop are measured to determine the friction factor, the Nusselt number, and the heat transfer coefficient. The same experiment is carried out to determine heat transfer through the same tube without any insert. Comparing the results obtained from these two different sets of experiments, it is found that heat transfer through tube can be enhanced by using inserts inside the tube up to 9.8 times than tube without insert.
\end{abstract}

Keywords: Heat Transfer Enhancement, Inserts, Pressure Drop, Turbulent flow

\section{Introduction}

Turbulent flow heat transfer in tubes with inserts has found wide applications in heat exchanger used in aerospace, vehicles, refrigeration and air conditioning, cooling of electronic equipments and so on. Improvement in the performance of above may results in the reduction of size of heat exchangers or higher heat transfer rate. Heat transfer and pressure drop characteristics in a circular tube fitted with full length strip, short-length strip, and regularly spaced strip elements connected by thin circular rods under uniform heat flux was investigated experimentally by Saha and Langille (2002). The strips were crossed-type, rectangular and square in cross-section with different aspect ratio. They found that friction factor was reduced by 8-58 percent and Nusselt number by 2-40 percent for short length strips. For regularly-spaced strips elements friction factor was increased by 1-35 percent and Nusselt number was increased by 15-75 percent. Hsieh and Huang (2000) experimentally studied the heat transfer and pressure drop characteristics of water flow on horizontal tubes with/without longitudinal inserts. The Reynolds number ranged from 1700 to 4000. The enhancement of heat transfer as compared to a conventional bare tube at the same Reynolds number based on the hydraulic diameter was found to be a factor of 16 at $\operatorname{Re} \leq 4000$, while the friction factor rise was only about a factor of 4.5 at $\operatorname{Re} \leq 4000$. Lin and Wang (2009) investigated heat transfer enhancement in circular tube with twisted tape insert. They reported that for fully developed laminar convective heat transfer, the thermal conduction in the tape obviously affects the overall heat transfer performance for the UWT condition. It has great influence on the local Nusselt number on the tube surface. Experimental investigations of heat transfer and friction factor characteristics of circular tube fitted with full length twisted tape with trapezoidal -cut were studied by Murugesan et al. (2009) for the Reynolds number range of 2000-12000. They reported a significant increase in heat transfer coefficient and friction factor for tape with trapezoidal-cut. Sarada et al. (2010) presented experimental results for the augmentation of turbulent flow heat transfer in a horizontal tube by means of varying width twisted tape inserts with air as the working fluid. They carried out experiments for plain tube with/without twisted tape insert at constant wall heat flux and different mass flow rates. Their results show the enhancement of heat transfer with twisted tape inserts as compared to plain tube varied from 36 to $48 \%$ for full width $(26 \mathrm{~mm})$ and 33 to $39 \%$ for reduced width $(22 \mathrm{~mm})$ inserts. 
Eiamsa-ard et al. (2010) experimentally investigated heat transfer, flow friction and thermal performance factor characteristics in a tube fitted with delta winglet twisted tape, using water as working fluid. Influences of the oblique delta-winglet twisted tape (ODWT) and straight delta-winglet twisted tape (S-DWT) arrangements were also described in their study. They mentioned that Nusselt number, friction factor and thermal performance factor in a tube with the O-DWT were1.04-1.64, 1.09-1.95, and 1.051.13 times of those in the tube with typical twisted tape (TT) respectively. Wazed et al. (2011) carried out an experimental investigation for turbulent flow in a circular tube with a porous/perforated twisted tape insert. They reported the enhancement of transfer coefficient in the cost of increasing pumping power. Ahamed et al. (2011) investigated turbulent flow in a tube with perforated twisted tape inserts. The mild steel twisted tape inserts with circular holes of different diameters (i.e., perforation) were used in the flow field. They also found that the pumping power, heat transfer coefficient, and effectiveness in the tube with the twisted tape inserts were increased compared to those for the plain tube for same Reynolds number, respectively. Moawed (2011) performed experimental investigation of heat transfer and friction factor characteristics of elliptic tubes with different twist ratios and pitch ratios under laminar flow condition and found that for a fixed Reynolds number, the friction factor increases with a decrease in twist ratios and pitch ratios for the elliptic tubes. A longitudinal rectangular plate insert in the tubes of heat exchanger is a good displaceable device and this enhances tube side heat transfer rate. The buoyancy effect on laminar forced convection in a circular tube with longitudinal thin rectangular plate insert was studied by Hsieh and Huang (2000). Sarkar et al. (2005) investigated the convective heat transfer in a tube with longitudinal inserts. At comparable Reynolds number, heat transfer coefficient in tube with longitudinal strip inserts is enhanced by 1.4 to 3 times, friction factor increased by 1.2 to 2.2 times while the pumping power increased up to 4 times compared to that of smooth tube.

The survey shows that heat transfer through tube can be enhanced significantly using inserts. However, the thermo hydraulic performance of tubes with rod-pin inserts is yet to be performed to best of our knowledge. This research focuses on the heat transfer performance of tube with rod pin insert. The objective of this study can be summarized as follows:

1. To develop an experimental facility for studying turbulent flow heat transfer and fluid friction in a tube with rod-pin inserts.

2. To analyze the heat transfer performance.

3. To compare the results obtained from both cases (Tube with and without insert).

4. To develop a correlation that may be recommended for the prediction of heat transfer coefficient in a tube with rod-pin inserts.

\section{Experimental setup and Methodology}

Figure 1 shows the experimental setup for conducting the experiment. The experimental facility consists of Test section, Inlet section, Air supply system and Heating arrangement. The rig is provided with inlet section for getting fully developed airflow in the test section. Experiments are carried out with Reynolds number in between $2.0 \times 10^{4}$ and $4.05 \times 10^{4}$. The test section is a circular tube made of Mild Steel $(1500 \mathrm{~mm}$ long and $68.5 \mathrm{~mm}$ inside diameter). The test section is wrapped with mica sheet, glass fiber tape and insulation tape. Over mica sheet Nichrome wire (of resistance $0.610 \mathrm{ohm} / \mathrm{m}$ ) is spirally wound uniformly with spacing 4 $\mathrm{mm}$ apart. Two heating coils are used to heat the test section. The insert is placed in the test rig with the help of bolted flanges. Asbestos sheets are placed which act as heat guards in the longitudinal direction. A $5 \mathrm{KVA}$ variable voltage transformer connected to $220 \mathrm{~V}$ AC power through a magnetic contactor and temperature controller is used to supply power to the test section's electric heater. The temperature controller is fitted to sense the air outlet temperature and give signal to heater for switching it off or on automatically. It protects the experimental set up from being excessively heated which may happen at the time of experiment when the heating system is operating continuously for hours to bring the system in steady state condition. It also controls the air outlet temperature. Four inserts with different longitudinal pin spacing $(50 \mathrm{~mm}, 100 \mathrm{~mm}, 150 \mathrm{~mm}$, and $200 \mathrm{~mm}$ ) are used in this study. The diameter of the rod is $20 \mathrm{~mm}$ and that of pin is $1.6 \mathrm{~mm}$. The pins are $15 \mathrm{~mm}$ long and the number of pin in radial direction is 8. The insert is shown in Figure 2. A motor operated suction type blower is fitted at downstream of the test section to supply air that will flow through the test section for ascertaining the heat transfer performance. A $12^{\circ}$ diffuser made of $1.5875 \mathrm{~mm}$ mild steel plate is fitted to the suction side of the blower. The diffuser is used for minimizing the head loss at suction side. To arrest the vibration of the blower a flexible duct is installed between the inlet section of the blower and the gate valve. The gate valve is of butterfly type and is used to control the flow rate of air. It is fitted at the suction side before the flexible duct. The electrical power to the test section is determined by measuring the current and voltage supplied to the heating element. The voltage is measured with a voltmeter and current by an $\mathrm{AC}$ ammeter. 


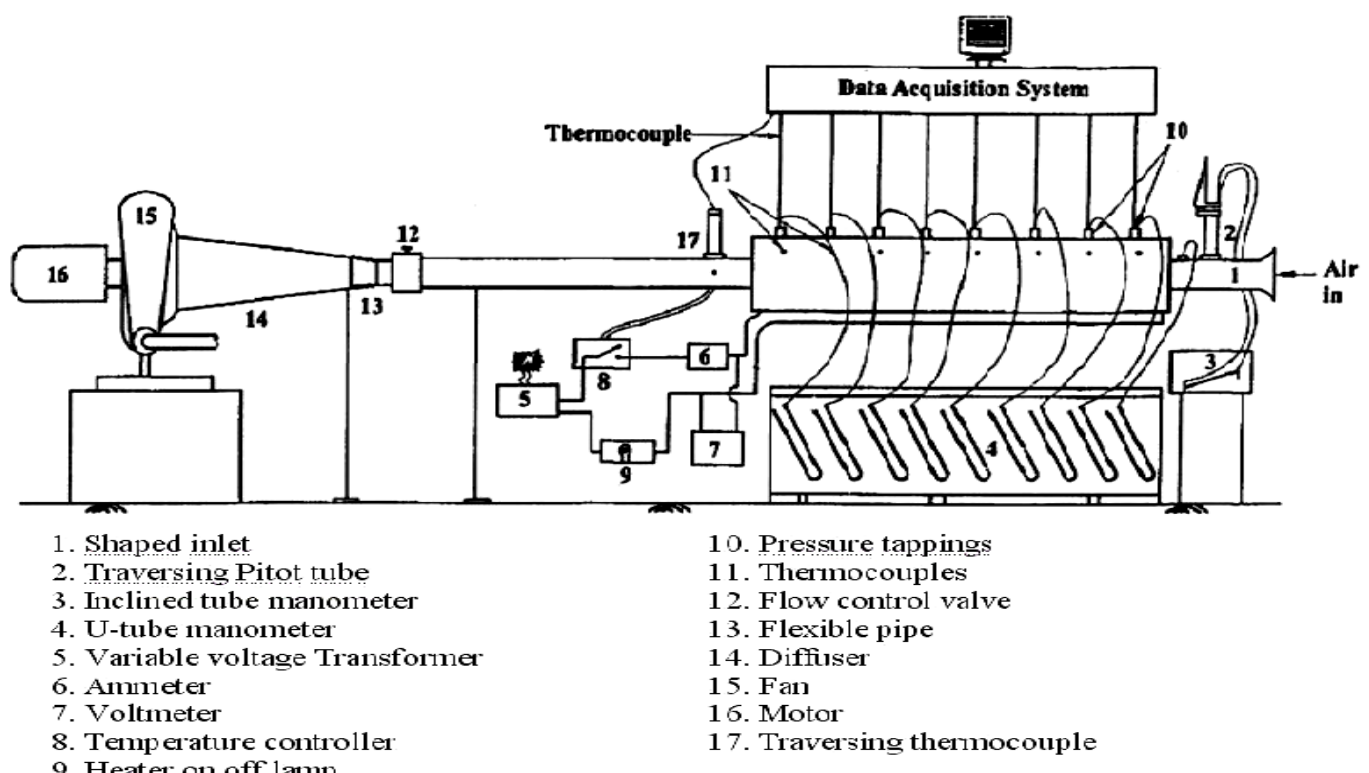

Figure 1. Schematic diagram of Experimental rig

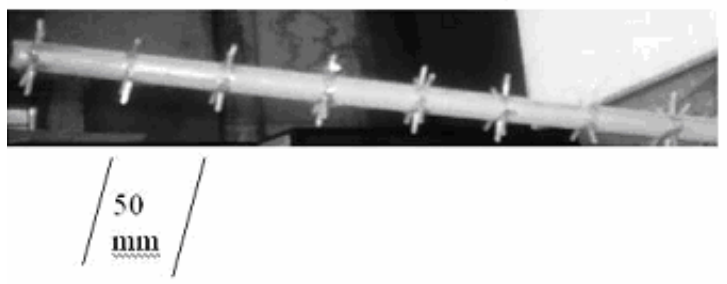

Pin diameter $=1.6 \mathrm{~mm}$

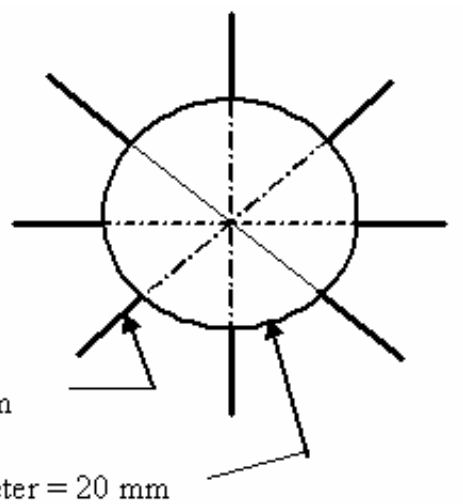

Figure 2. Rod-pin inserts (pin distance, $x=50 \mathrm{~mm}$ )

The Blower is first switched on and allowed to run for few minutes to have the transient characteristics died out. The flow of air through the test section is set to desired value and kept constant with the help of a flow control valve. Then the electric heater is switched on. The electric power is adjusted with the help of a regulating transformer or variac. First, the variation in wall thermocouples is observed until constant value is attained, and then the outlet air temperature is monitored. Steady state condition was attained when the outlet air temperature does not deviate over 10-15 minutes time. At the steady state condition thermocouple and manometer readings are taken manually. After each experimental run, the Reynolds number is changed with the help of the flow control valve, keeping electrical power input constant. Flow of air through the test section is measured at the inlet section with the help of a traversing pitot. The traversing pitot is fitted at a distance of 4 times of diameter from the inlet. The manometric fluid used here is high-speed diesel gravity 0.855 . Arithmetic mean method is employed to determine the position of the Pitot tube for determination of mean velocity. The static pressure tappings are made at the inlet of the test section as well as equally spaced 8 axial locations of the test section. The outside parts of the tappings are made tapered to ensure an airtight fitting into the plastic tubes, which were connected top the manometer. The temperatures at the different axial locations of the test section are measured with the K-type thermocouples.

\section{Results and Discussions}

Experiments are carried out for both smooth tube and tube with insert. In this paper, tube without insert and smooth tube carry the same meaning. To keep the volume of the paper, only representative figures and results are provided. 

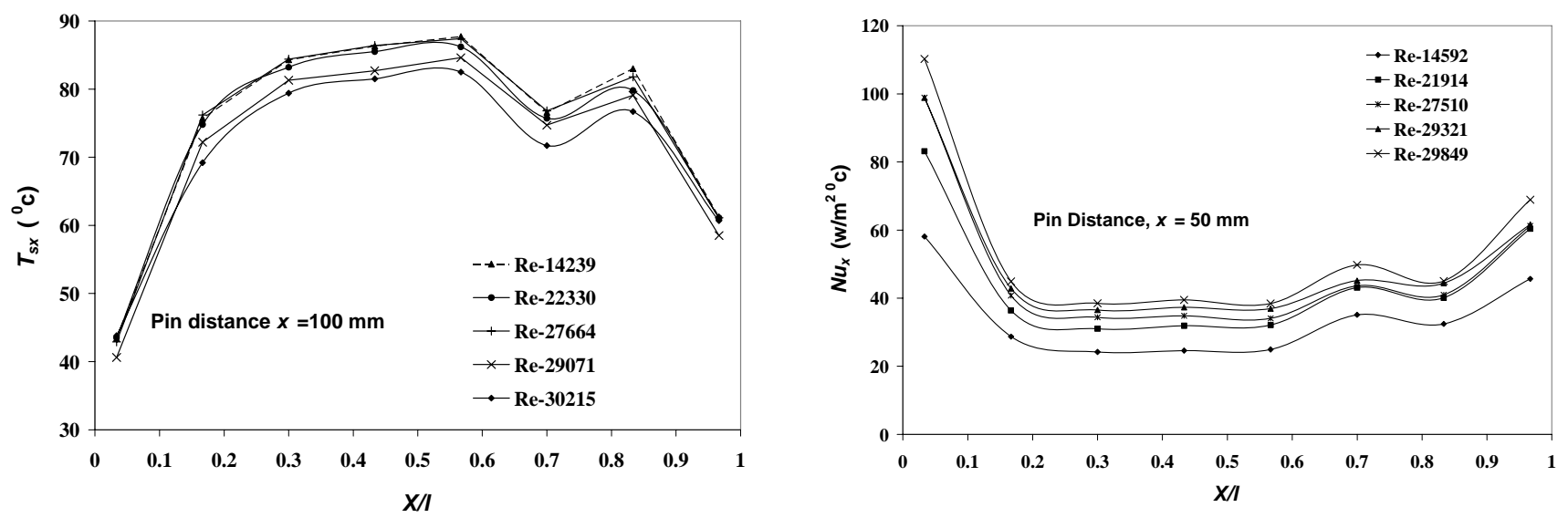

Figure 3. Tube surface temperature along the length of the tube Figure 4. Local Nusselt Number along the length of the tube

Figure 3 shows the longitudinal variation of tube surface temperature for tube with insert. The results are plotted against $(x / l)$, where $x$ is the axial position of any point and is nondimensionalized by the total length of the insert. This is plotted for different Reynolds Number. Because of the conduction heat losses, the tube surface temperatures at the entry and exit portions are lower. Tube surface temperature is also lower for higher Reynolds Number indicates more heat is taken by air, flowing through the tube. Nusselt number is higher at entrance region and gradually decrease, again increase at the down stream along longitudinal direction of the test section (Figure 4). Figure 5 compares Nusselt number for smooth tube and tube with rod-pin insert. This curve is plotted for Reynolds Number between $1.4 \times 10^{4}$ and $4.4 \times 10^{4}$. For tube with rod-pin inserts (pin distance $50 \mathrm{~mm}$ ) Nusselt number is about 4 times higher than that of smooth tube at Reynolds number $1.4 \times 10^{4}$ and is 1.16 times higher at Reynolds number $3.9 \times 10^{4}$. For insert with pin distance $100 \mathrm{~mm}$ this ratio becomes 3.5 times at Reynolds number $1.4 \times 10^{4}$ and 1.36 times at Reynolds number 3.9 $\times 10^{4}$. Similarly the ratio for $150 \mathrm{~mm}$ and $200 \mathrm{~mm}$ pin distance are about 4 times at $1.4 \times 10^{4}, 1.32$ times $3.9 \times 10^{4}$ and about 3.63 times at Reynolds number $1.4 \times 10^{4}, 1.46$ times at Reynolds number $3.9 \times 10^{4}$. The local friction factor based on hydraulic diameter is given by Eq. (1)

$$
f=\frac{(-\Delta P / X) D_{h}}{2 \rho V^{2}}
$$

Where $\Delta P$ is the pressure drop, $\mathrm{X}$ is the axial location, Dh hydraulic diameter, $\rho$ density of air and $\mathrm{V}$ is the velocity of air. The variation of friction factor along the length of the tube is shown in Figure 6. It shows that the friction factor decreases along the length of the test section. Friction factor is high near the entrance region and then falls gradually. The rod pin insert increases the wetted perimeter, reduces the flow cross sectional area, and because of the fluid has to flow a partitioned path with wires, it increases the flow length. The effect is that higher pressure drops and heat transfer coefficients are obtained in comparison with those for equivalent smooth tube flows.

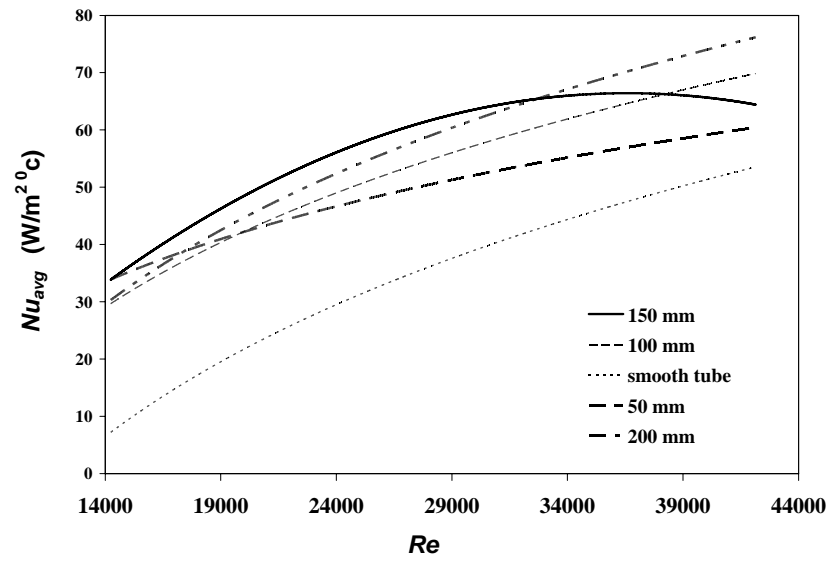

Figure 5. Comparison of avg. Nusselt number

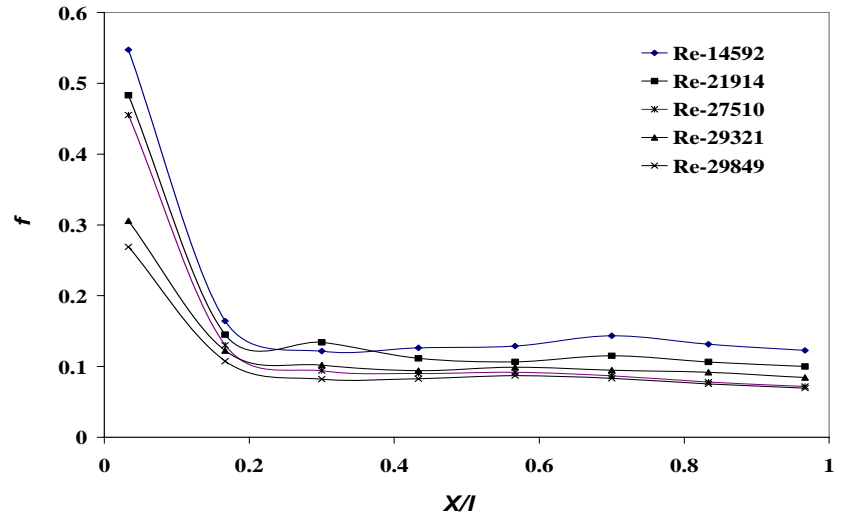

Figure 6: Local Friction factor along the length of the tube

Figure 7 compares blower power for smooth tube and tube with different inserts. It shows that Blower power increases with higher Reynolds number for smooth tube and tube with inserts. The presence of small vortices around the insert is responsible for 
the higher pressure drop and thereby higher pumping power. Extra Blower power is needed to overcome adverse increasing pressure drop with decreasing Pin distance.

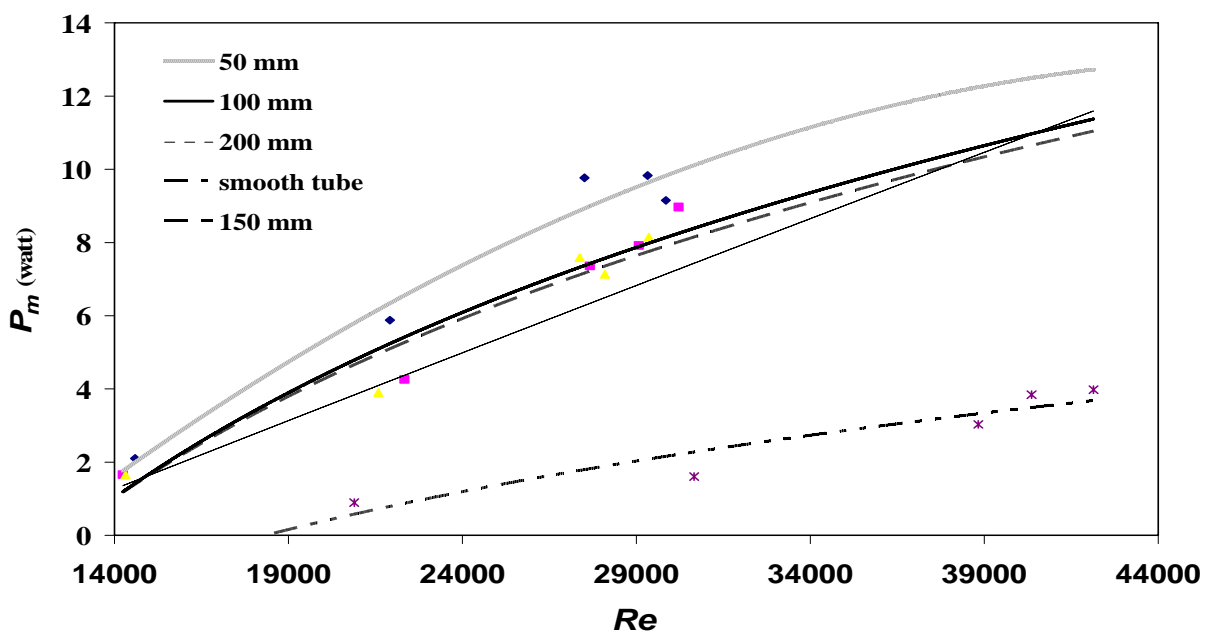

Figure 7. Comparison of pumping power for smooth tube and tube with inserts

Finally, a correlation is also developed.

$$
N u=\left(2 e^{-05} x^{2}-0.0071 x+0.5212\right) \times \operatorname{Re}^{\left(-9 e^{-05} x^{2}+0.0242 x-0.3228\right)} \operatorname{Pr}^{.33}
$$

The Nusselt numbers predicted from Eq. (2) are agreed well with the experimental values.

\section{Uncertainty Analysis}

A precise method of estimating uncertainty in experimental results is described by Kline and McClintock (1953). If the result $\mathrm{R}$ is a given function of the independent variables $\mathrm{X} 1, \mathrm{X} 2, \mathrm{X} 3, \ldots \ldots \ldots \ldots \mathrm{Xn}$ andt $\mathrm{G} 1, \mathrm{G} 2, \mathrm{G} 3, \ldots \ldots \ldots \ldots \mathrm{Gn}$ be the uncertainty in the independent variables given with the same odds.

Then the uncertainty in the result having this same odd is given in Eq. (3)

$$
G_{R}=\left[\sum_{i=1}^{n}\left(\frac{\partial R}{\partial X_{i}} \times G_{i}\right)^{2}\right]
$$

Using Eq. (3) and the uncertainty of primary measurands, the uncertainty of air velocity and heat transfer are calculated as $1.816 \%$ and $8.19 \%$ respectively.

\section{Conclusions}

An experimental study is conducted to investigate the heat transfer characteristics in a tube by means of rod-pin inserts. The study has revealed that the rod-pin inserts in the tube enhances heat transfer rate at the cost of increased pumping power. The following conclusion can be made.

o For comparable Reynolds number heat transfer coefficient for tube with inserts is higher than that of smooth tube by

1. Up to 4.1 times when $\mathrm{x}=50 \mathrm{~mm}$

2. Up to 4.2 times when $x=100 \mathrm{~mm}$

3. Up to 4.4 times higher when $\mathrm{x}=150 \mathrm{~mm}$ and

4. Up to 4 times higher for $\mathrm{x}=200 \mathrm{~mm}$.

o The pumping power required for tubes with rod-pin inserts may be up to 6 times higher than smooth tube.

o The Nusselt number is high in the entrance region and it decreases gradually up to a certain point corresponding to the value of a fully developed flow.

o It is observed that tube with rod-pin insert having pin distance $150 \mathrm{~mm}$ performs better.

o In future, numerical analysis will be carried on to verify the experimental results and to determine the optimal geometry of insert for maximum heat transfer enhancement. 
o Study with different geometries of inserts (Other than twisted tape or rod-pin but may be combination of these two or new geometry) can be done.

\section{Acknowledgement}

The authors are grateful to K.M Hasan and Professor S.M.N Islam for helpful discussions and their valuable suggestions.

\section{References}

Ahamed, J. U., Wazed, M. A., Ahmed, S., Nukman, Y., Tuan Ya, T. M. Y. S., Sarkar, M. A. R. 2011. Enhancement and Prediction of Heat Transfer Rate in Turbulent Flow through Tube with Perforated Twisted Tape Inserts: A New Correlation. Journal of Heat Transfer, Vol. 133, No. 041903, pp. 1-9

Eiamsa-ard, S., Wongcharee, K., Eiamsa-ard, P., Thianpong, C. 2010. Heat transfer enhancement in a tube using delta-winglet twisted tape inserts. Applied Thermal Engineering, Vol. 30, pp. 310-318

Hsieh, S.S. and Huang, I.W. 2000. Heat Transfer and Pressure Drop of Laminar Flow in Horizontal Tubes With/Without Longitudinal Inserts. Journal of Heat Transfer, Vol.122, pp. 465-475.

Kline, S. J., McClintock, F. A. 1953. Describing Uncertainties in Single-Sample Experiments. Mech. Eng., pp. 3.

Moawed, M. 2011. Heat transfer and friction factor inside elliptic tubes fitted with helical screw-tape inserts. Journal of renewable and Sustainable Energy, Vol. 3, No. 023110, pp.1-15

Murugesan, P., Mayilsamy, K., Suresh, S., Srinivasan, P.S.S. 2009. Heat transfer and pressure drop Characteristics of turbulent flow in a tube Fitted with trapezoidal-cut twisted tape insert. International Journal of Academic Research, Vol. 1, No. 1, pp. $123-128$

Saha, S.K. and Langille, P. 2002. Heat Transfer and Pressur Drop Characteristics of Laminar Flow Through a Circular Tube With Longitudinal Strip Inserts Under Uniform Wall Heat Flux. Journal of Heat Transfer, Vol. 124, pp.421-432

Sarada, S.N., Raju, A.V.S.R, Radha, K.K., Sunder, L.S. 2010. Enhancement of heat transfer using varying width twisted tape inserts. International Journal of Engineering, Science and Technology. Vol. 2, No. 6, pp. 107-118

Sarkar, M. A. R., Hasan, A B M T, Ehsan, M. Talukdar, M M A, Huq, A M A. 2005. Heat Transfer in Turbulent Flow through Tube with longitudinal Strip Inserts, Proceedings of the International Conference on Mechanical Engineering. ICME05-TH-46

Wazed, M.A., Ahamed, J. U., Ahmed, S., Sarkar, M. A. R. 2011. Enhancement of heat transfer in turbulent flow through a tube with a Perforated twisted tape insert. Journal of Enhanced Heat Transfer. Vol. 18, No. 1, pp. 1-13

Zhi-Min Lin and Liang-Bi Wang. 2009. Convective Heat Transfer Enhancement in a Circular Tube Using Twisted Tape. Journal of Heat Transfer. Vol. 131 pp. 1901-12

\section{Biographical notes}

M.A.K. Chowdhuri received his B.Sc and M. Sc from Bangladesh University of Engineering and Technology (BUET). He is an Assistant Professor in the Department of Mechanical Engineering, BUET, Bangladesh. Presently he is on leave from BUET for his higher studies at University of Alberta, Canada. His research interests include heat transfer engineering, composite mechanics, interface mechanics, instrumentation and control. He is an associate member of Institution of Engineers, Bangladesh.

R.A. Hossain received her B.Sc and M. Sc from Bangladesh University of Engineering and Technology (BUET) in 2006 and 2008 respectively. She is currently doing her Ph.D in Mechanical Engineering of University of Alberta, Canada. Her research interests include heat transfer, bio mechanics and composite mechanics.

M.A.R Sarkar is a Professor in the Department of Mechanical Engineering, Bangladesh University of Engineering and Technology (BUET), Bangladesh. He has more than 15 years of experience in teaching and research. His current area of research includes Heat Transfer, Robotics and Control Engineering. He was the Dean of mechanical engineering faculty for the last two years. He has published many papers in referred international journals. He is currently dealing with few important and valuable projects.

Received December 2010

Accepted June 2011

Final acceptance in revised form June 2011 